\title{
The Evolution of Multiple Memory Systems
}

\author{
David F. Sherry and Daniel L. Schacter \\ University of Toronto, Toronto, Ontario, Canada
}

\begin{abstract}
The existence of multiple memory systems has been proposed in a number of areas, including cognitive psychology, neuropsychology, and the study of animal learning and memory. We examine whether the existence of such multiple systems seems likely on evolutionary grounds. Multiple systems adapted to serve seemingly similar functions, which differ in important ways, are a common evolutionary outcome. The evolution of multiple memory systems requires memory systems to be specialized to such a degree that the functional problems each system handles cannot be handled by another system. We define this condition as functional incompatibility and show that it occurs for a number of the distinctions that have been proposed between memory systems. The distinction between memory for song and memory for spatial locations in birds, and between incremental habit formation and memory for unique episodes in humans and other primates provide examples. Not all memory systems are highly specialized in function, however, and the conditions under which memory systems could evolve to serve a wide range of functions are also discussed.
\end{abstract}

Memory is a function that permits animals and people to acquire, retain, and retrieve many different kinds of information. It allows them to take advantage of previous experience to help solve the multitude of problems with which their environment confronts them, such as how to recognize the familiar, predict events, return to particular places, and assess the consequences of behavior. Recently the question has arisen as to whether the diverse phenomena of memory all depend on a single underlying system or whether they depend on multiple systems. Investigators in a number of areas, including neuropsychology, cognitive psychology, and animal learning, have argued that it is useful and perhaps necessary to postulate the existence of multiple memory systems.

Several different types of evidence have been cited in support of the nonunitary view, including selective memory deficits in amnesic humans and animals, experimentally induced dissociations in normal subjects' performance of various memory tasks, and ethological observations of unusual or idiosyncratic learning abilities (e.g., Cohen \& Squire, 1980; Hirsh, 1974; Mishkin, Malamut, \& Bachevalier, 1984; O’Keefe \& Nadel,

This research was supported by a Special Research Program Grant from the Connaught Fund of the University of Toronto and by Natural Sciences and Engineering Research Council of Canada Grants UO361 to Daniel L. Schacter and A1058 to David F. Sherry.

We would like to thank Fergus Craik, Victoria Esses, Luc-Alain GiraIdeau, Robert Lockhart, David Olton, Paul Rozin, Sara Shettleworth, Larry Squire, Endel Tulving, and Derek Van der Kooy for their many helpful comments and Carol Macdonald for her help with preparation of this article.

The order of authorship was determined by a coin toss at the Young Lok Restaurant, where most of the article evolved.

Correspondence concerning this article should be addressed to David F. Sherry, Department of Psychology, University of Toronto, Toronto, Ontario, Canada M5S $1 \mathrm{~A} 1$ or to Daniel L. Schacter, who is now at the Department of Psychology, University of Arizona, Tucson, Arizona 85721.
1978; Olton, Becker, \& Handelmann, 1979; Rozin \& Kalat, 1971; Schacter \& Moscovitch, 1984; Shettleworth, 1972; Squire \& Cohen, 1984; Tulving, 1983). Some researchers are not convinced of the need to postulate the existence of multiple memory systems, however, and maintain that the experimental evidence does not mandate rejecting the view of a unitary learning and memory system that is explainable by a single set of general principles or laws (Bitterman, 1975; Craik, 1983; Jacoby, 1983, 1984; Kolers \& Roediger, 1984; Logue, 1979; MacPhail, 1982; Revusky, 1977).

The purposes of this article are to determine whether there are evolutionary grounds for favoring a unitary or a nonunitary view of memory and to bring together recent research on memory systems in humans and animals that bears on this problem. The principal question we address is whether the evolution of qualitatively distinct memory systems would be expected to occur or whether a single memory system that is characterized by increasing complexity and flexibility is the expected evolutionary outcome. We develop an argument that favors the former alternative and that is based on the idea of functional incompatibility between environmental demands and the properties of memory systems. Functional incompatibility is an extension of an idea advanced previously by Rozin and his colleagues (Rozin, 1976a; Rozin \& Kalat, 1971; Rozin \& Schull, in press). They argued that memory and learning abilities in animals are adaptive specializations, shaped by natural selection to solve specific problems posed by an animal's environment. We will suggest that functional incompatibility exists when an adaptation that serves one function cannot, because of its specialized nature, effectively serve other functions. The specific properties of the adaptation that make it effective as a solution to one problem also render it incompatible with the demands of other problems. We will describe several situations in which adaptive specializations of memory are functionally incompatible with the solution of other problems in learning and memory. When selection has produced such a specialized memory system, any additional memory capacities that evolve require a new, qualitatively different memory system. 
Although the idea of functional incompatibility is the cornerstone of our argument, we also employ the concept of exaptation, which describes a feature of an organism that increases fitness by some means, but was not selected for that role (Gould \& Vrba, 1982). Exaptations are adaptations to one environmental problem that can be co-opted to solve a new problem. Despite our conclusion that memory is nonunitary, not every environmental problem has its own dedicated memory system, and few memory systems have only a single function. Most memory systems deal with a great variety of problems, whether as adaptations or fortuitously. We suggest that when environmental demands and consequent selection pressures produce a memory system that can provide solutions to problems other than the one for which it has been selected, the system may be co-opted for use in other situations. Under these conditions, selection does not result in the emergence of a new memory system because an existing system is capable of handling novel problems.

We hope to show that the foregoing ideas can help us understand how qualitatively distinct memory systems may have arisen in the course of evolution and, hence, can help us accommodate observations of specificity and uniqueness in different types of memory. At the same time, they may also allow us to account for some of the generality in learning and memory across situations and species. We will therefore suggest that it may be possible to achieve a rapprochement between those who have emphasized the unique properties of specific types of memory and those who have emphasized the general properties that are shared by many types of memory.

This article is divided into five sections. The first defines and discusses the terms memory system and multiple memory systems as we will use them. The second presents the evolutionary concepts that are the basis for the subsequent discussion. The next section considers functional incompatibility in animals, focusing on song learning and spatial memory in birds. We suggest that the available data provide reasonable support for the view that these phenomena are mediated by memory systems that are qualitatively distinct. The fourth section turns to multiple memory systems in humans and other primates. It begins by describing data that have been used to support the idea of multiple memory systems and then considers these results and the distinctions that have been proposed to accommodate them in light of the evolutionary argument. The final section considers several general issues in the study of learning and memory as well as the value of an evolutionary approach.

\section{What Is a Memory System?}

Because our major task is to discuss the evolution of memory systems, it is important to state explicitly what we mean by memory system and multiple memory systems. In this article, the term memory system refers to an interaction among acquisition, retention, and retrieval mechanisms that is characterized by certain rules of operation. The term multiple memory systems refers to the idea that two or more systems are characterized by fundamentally different rules of operation.

Within the general framework of these definitions, it is possible to distinguish two views of memory systems, which we will call the strong and weak views. By the strong view, a memory system is a functionally autonomous unit in which the compo- nent processes interact exclusively with one another and operate independently of other such units. In this scenario, different memory systems not only operate according to different rules but also share no component processes. By the weak view, a memory system is an interaction among component acquisition, retention, and retrieval processes in which any of the components can interact with other processes outside the system. In this scenario, different systems share some components but are still defined by specific interactions among the processes that make up the system.

At the present time, we cannot provide empirical evidence that one of these two conceptualizations is more appropriate than the other. Nevertheless, because the weak view entails less stringent assumptions than does the strong view, we will adopt it in the present discussion. The evolutionary ideas we discuss are applicable to either view, although the details of how they apply may differ under the strong and weak views.

Another important point, which holds in either the strong or weak view of memory systems, concerns the distinction between the type of information handled by a memory system and the rules by which the system handles that information. According to our usage, it is only justifiable to speak of multiple memory systems when the systems are characterized by different rules of operation. The fact that many different types of information are represented in memory need not imply that the mechanisms responsible for acquiring, retaining, and retrieving specific types of information operate according to different rules. Similarly, the possibility that memory for different types of information is handled by distinct regions of the brain need not imply the existence of multiple memory systems operating according to distinct rules.

The implications of this idea can be clarified by considering recent notions of modular cognitive organization. A number of theorists have argued that analysis of different types of information, such as facial, linguistic, and spatial information, is handled by different processors or modules (Fodor, 1983; Gazzaniga, 1985; Marshall, 1984; Neisser, in press; Shallice, 1981). Modules perform domain-specific computations and operate largely independently of one another. The question of whether each module has is own memory system has not yet been addressed in any detail, but consideration of the alternatives is instructive. One possibility is that all modules output to a common memory system and gain access to this information via a common retrieval mechanism. This is a relatively clear case of a unitary memory system. A second possibility is that each module has its own memory system but that each of these module-specific memories operates according to the same rules. Information about faces is stored and retrieved by the faces module, information about space is stored and retrieved by the space module, but memory in each case operates in the same way. We would not call this state of affairs multiple memory systems either. Although in this case module-specific information might even be represented in neurologically distinct places, the rules of operation are the same across modules, and the same interaction among component processes recurs. There is a third possibility, however, that each module has its own acquisition, retention, and retrieval processes and that the rules of operation of these processes differ across modules. According to our usage of the term, only here do we find multiple memory 
systems. The point of these considerations is to emphasize that the existence of domain-specific modules that process different types of incoming information need not imply multiple memory systems.

\section{An Evolutionary View of Memory Systems}

In this section we examine the components of an evolutionary analysis of memory: natural selection, heritable variation in memory, memory and reproductive success, and adaptive specialization. Building on these foundations, we elaborate the idea of functional incompatibility.

\section{Natural Selection}

Darwin's argument for natural selection as the principal means of evolutionary change consisted of three steps (Darwin, 1859). The first was the observation that only a small part of each generation survives to reproduce. The second was that although like begets like among living things, there is inherent variability in this process. Offspring are not identical to their parents, and offspring of the same parents are rarely identical to each other. Each generation exhibits variation, and most important, some of this variation is heritable. Darwin's final observation was that some components of heritable variation, compared with others, confer a greater likelihood that their bearer will survive and reproduce. This is the process of natural selection, which Darwin so named in an explicit analogy to the process by which plant and animal breeders select from among the variation that occurs in domesticated species. Nature, however, selects not on the basis of traits that might seem useful or attractive to an animal breeder, but on the basis of traits that differentially affect reproductive success. The resulting change in the frequency of heritable traits is the origin of evolutionary change.

The effect on reproductive success of a particular feature of anatomy, physiology, or behavior depends on the environment in which it occurs. Selection by the environment produces adaptations, or traits that solve the problems posed by the environment with such precision that they may give the impression of having been intelligently designed for their function. Memory, if it is acted on by natural selection, will show adaptations that are solutions to problems posed by the environment.

\section{Heritable Variation in Memory}

For natural selection to act on memory there must be heritable variation in this trait. How much genetic variation is available in natural populations for selection to act on is a difficult problem in evolutionary biology, made more so because intense selection for a trait may reduce the amount of genetic variation that can be detected. Certainly no attempt has been made to estimate the degree of genetic variation in memory mechanisms in natural populations. We can proceed along a different track, however, because in some animals direct genetic effects on memory have been isolated.

A strain of the fruitfly Drosophila called dunce differs from its parental strain at only a single genetic locus. But it is unable, because of this single gene difference, to learn to avoid odors that have been paired with electric shock (Dudai, Jan, Byers, Quinn, \& Benzer, 1976). It can discriminate among the odors used in training, and it responds normally to shock during training and shows normal locomotion, flight, and other behavior. But dunce shows no greater avoidance of an odor previously paired with shock than of a control odor. Wild-type Drosophila can learn this avoidance task with as few as three training trials. Dudai (1979) has described another allele at the dunce locus that makes fruitflies unable to retain the effects of training if an additional odor is presented between training and testing. A further Drosophila memory mutant called amnesiac (Quinn, Sziber, \& Booker, 1979) can acquire the avoidance of an odor paired with shock but, when tested more than $15 \mathrm{~s}$ after training, shows deficits relative to controls.

How a difference at a single genetic locus might lead to a difference in memory can be appreciated from the variety of known genetic effects on the organization and development of the nervous system. Genetic effects on the release of neurotransmitter at the synapse and on long-term facilitation of synaptic transmission are known for Drosophila (Quinn \& Gould, 1979), as are genes that affect the sodium and potassium ion channels of the neural membrane (Burnet \& Connolly, 1981). The dunce mutation affects the metabolism of cyclic AMP; the biochemical effect of amnesiac is not clear (Quinn \& Greenspan, 1984). In other species, the links between genetic variations and their effects on the nervous system and ultimately on learning and memory are beginning to be understood. Sidman, Green, and Appel (1965) have cataloged more than 100 mutations that affect the development and structure of the nervous system in mice. Hybridization studies and the study of singlegene mutants have revealed genetic effects on the electrical activity, branching processes, and acetylcholinesterase activity of mouse neuroblastoma cells and on the orientation and migration during development of mouse cerebellar, hippocampal, and cortical neurons (Bentley, 1976). The single-gene mouse mutation, weaver, affects dopamine-containing fiber systems in one part of the brain but not in another (Roffler-Tarlov \& Graybiel, 1984).

These results show that differences in genotype can produce differences in the nervous system with major consequences for memory. How natural selection might act on individuals with different genotypes affecting memory is described in the next section.

\section{Memory and Reproductive Success}

Heritable differences in memory will have evolutionary consequences only if these differences lead to differential survival and reproduction by their bearers. Natural selection must act on the behavioral consequences of differences in memory before changes in the frequencies of memory traits will occur. We will briefly describe several cases in which the selective advantage of memory seems clear.

Avoiding predation. Many birds harass potential predators and drive them away, a behavior known as mobbing. Mobbing is particularly intense near the nest. Vieth, Curio, and Ernst (1980) have shown that recognition of potential predators can be learned by naive European blackbirds (Turdus merula) by observing mobbing by experienced individuals. Demonstrator 
blackbirds were induced to mob a familiar predator in the laboratory. Observer blackbirds saw only the mobbing behavior and a novel but harmless animal, the predator being out of view. When observers were later tested alone, they mobbed the novel model, whereas blackbirds that had seen the model but not the mobbing did not. Later tests showed that the observers that had acquired "predator recognition" of a nonpredator could induce mobbing of this animal in other naive blackbird observers $(\mathrm{Cu}$ rio, Ernst, \& Vieth, 1978a, 1978b).

This experimental result indicates that observer blackbirds remembered the animal they had previously seen mobbed. This information was retained in the complete absence of any predatorlike behavior by the harmless model. In nature, of course, the ability to remember and recognize animals that others treat as predators would clearly contribute to protection of the nest and young.

Animal contests. Animals compete over resources such as food, territories, and mates. If the same individuals compete repeatedly, memory for the outcome of previous contests can reduce the costs of competition for both the winners and losers of previous contests. Dominance hierarchies within social groups are often maintained with little overt fighting once the ranking of individuals has been established. Individual recognition and memory for the outcome of previous contests are not essential to the formation of dominance hierarchies (Barnard \& Burk, 1979), but they can be shown to occur in many cases (Colgan, 1983). Reduction of the costs of fighting, in terms of both reduced likelihood of injury and increased time available for feeding and other activities, would favor a memory system capable of individual recognition.

The outcome of animal contests may depend on learning and memory (Hollis, 1984). Fish that are defending breeding territories fight more effectively if they have had the opportunity to associate the intrusion of other fish with cues that predict these intrusions. The increase in the effectiveness of territorial defense occurs because animals that have associated predictive cues with intrusions are more prepared to fight. They fight with greater intensity and after a shorter latency than unprepared animals. This preparatory function of learning and memory is probably a very pervasive effect in feeding, predator avoidance, courtship, parental care, and other behaviors (Hollis, 1982, 1984).

Cooperation and altruism. The evolution of altruism, according to current theory, requires that helping be directed preferentially toward individuals likely to share the genetic predisposition for altruism (Hamilton, 1964). Discriminating among relatives and nonrelatives is central to this idea. Precise individual recognition is not necessary, but discrimination among related and nonrelated conspecifics, on the basis of experience, has been shown to occur in swallows, ground squirrels, bees, and other species (Holmes \& Sherman, 1983).

Trivers's (1971) model of the evolution of altruism is an alternative to Hamilton's (1964) inclusive fitness model in that it requires no genetic relatedness between altruist and beneficiary but, instead, requires repeated interactions among individuals that recognize one another and remember whether previous altruistic acts have been reciprocated. The conditions of Trivers's (1971) model are met by aid giving in vampire bats (Wilkinson, 1984) and olive baboons (Packer, 1977), and altruism is medi- ated in these species by individual recognition of some kind. Memory systems equal to these tasks would be expected to be favored by natural selection to at least the same degree as altruism itself.

Foraging. Optimization models of foraging assume that animals possess information on the expected distribution and abundance of food. Optimal patch-use models, for example, require that animals possess some estimate of the travel time between patches (Pyke, Pulliam, \& Charnov, 1977). Risk sensitivity in foraging requires animals to respond to variances in food availability, the estimation of which requires the retention of some components of previous experience (Caraco, 1981; Stephens, 1981; Stephens \& Charnov, 1982). Clearly, foraging animals are not omniscient, and how this information is acquired is one of the most challenging questions in the study of foraging (Krebs, Stephens, \& Sutherland, 1983). Natural selection would be expected to favor systems of memory that permit efficient exploitation of available food resources.

This list of selective advantages of learning and memory is far from exhaustive. It illustrates instead the variety of problems in which variation in learning and memory capacities could be the basis for selection and evolutionary change in these capacities.

\section{Adaptive Specialization}

"The concept of adaptation implies a preexisting world that poses a problem to which an adaptation is the solution" (Lewontin, 1978 , p. 213). We have tried to show that natural selection can act on memory as it does on other properties of the nervous system to produce solutions to specific environmental problems (see also Bruce, 1985; Northcutt, 1984; Rozin, 1976a).

The existence of adaptive specializations in learning and memory was originally proposed to account for the unusual learning abilities of some animals, notably the ability of rats to associate eating toxic food with effects that followed several hours later (Rozin \& Kalat, 1971). The formation of an association over such a long delay, and the selective association of the flavor of food with illness, as opposed to the association of its appearance or location with illness, were regarded as environmental problems unusual enough to select for a memory system specialized to help avoid toxic food. The capacity to form these associations was unexpected, given what was known about animal learning and memory from laboratory paradigms (Garcia, Ervin, \& Koelling, 1966; Garcia \& Koelling, 1966). More recently, with the benefit of a few minor modifications, general process learning theory has proved more capable of accounting for this result than was initially supposed (Logue, 1979; Roper, 1983). But the idea of adaptive specializations of learning in different species of animals has remained an influential one, even if unequivocal examples of it have been scarce (Shettleworth, 1983). Although most objections to general process theories of learning focus on differences between species (Bolles, 1970; Garcia, Hankins, \& Rusiniak, 1974; Hinde, 1973; Johnston, 1981; Seligman, 1970; Shettleworth, 1972), we will stress, as did Rozin and Kalat (1971), that these differences necessarily imply different memory systems within an animal's nervous system. 
Adaptive specializations, then, are memory capacities that are distinguishable from other kinds of memory and that are used in situations in which their rules of operation make them especially suitable for the solution of a particular environmental problem. As Rozin and Kalat (1971) put it, "This thesis . . . emphasizes differences in learning mechanisms themselves, as a function of the situations in which learning occurs" (p. 460). The "adaptive" component refers both to modification of mechanism and to function, and "specialization" to the use of this mechanism in a restricted set of situations.

Williams (1966) has argued that adaptation is a concept that must be employed cautiously. Not all traits that seem useful are necessarily adaptations. Gould and Lewontin (1979) have criticized what they regard as a tendency to find adaptations in all features of organisms. Mayr (1983) has rebutted a number of Gould and Lewontin's specific criticisms, but lest our own emphasis on adaptations in memory be misunderstood, a few points should be clarified. First, not all aspects of memory should be thought of as adaptations to solve specific problems. Indeed, the idea that memory possesses many nonadaptive features is part of our argument for exaptation. Second, there is no supposition either in this article or in modern evolutionary thought that natural selection produces perfection. Adaptations are the result of selection acting on whatever heritable variation is available. Third, evolution is not prescient. It does not anticipate future requirements and equip organisms with adaptations to meet them. Natural selection, as Futuyma $(1986$, p. 7$)$ put it, "has no purpose or goal."

\section{Functional Incompatibility}

Selection is expected to produce adaptations in memory that deal with particular problems in the acquisition, storage, and retrieval of information. But evolutionary change of this kind does not necessarily lead to multiple memory systems. Evolutionary change and the various adaptations that result could occur within a unitary memory system. The reason, we will argue, that the evolutionary outcome has been multiple memory systems rather than a single system capable of serving many functions is that the memory system that effectively solves some environmental problems may be unworkable as the solution to others. The kind of memory used by birds, for example, to learn the songs they sing, or by humans to learn certain skills, may be incompatible with an effective solution to other memory problems. The incompatibility arises in one sense from constraints imposed by the kind of solution used for each problem, but it is ultimately imposed by the nature of the problems themselves.

Although multiple memory systems all perform functions we can recognize as memory in a broad sense, these functions differ in ways that make the adequate solution of one problem incompatible with the solution of another using the same mechanism. Cases in which multiple systems serve seemingly similar functions, but in fact differ in important respects, are relatively common in the biological world. Most insects possess two kinds of eyes, compound eyes placed laterally on the head and ocelli located frontally. Both are sophisticated adaptations with lenses that focus light and receptor cells that convey information to the nervous system (Chapman, 1982). The compound eyes are capable of fine spatial resolution and pattern perception. The ocelli are not, because although the lens focuses light, its focal plane lies behind the ocellar retina, producing an image that is out of focus. Ocelli probably detect only average illumination across their entire visual field, but they do this with great sensitivity (Wilson, 1978). Because of their large neurons and the small number of integrative steps in the neural pathway, ocelli convey information to the nervous system more rapidly than do compound eyes (Wilson, 1978).

Both ocelli and compound eyes help stabilize flying insects against roll and pitch during flight. Why should there be a dual visual system for the control of orientation in flight? Probably because of functional incompatibility. Fine resolution by the compound eye is achieved at the cost of a slow response time and a reduced ability to detect changes in average light intensity (Taylor, 1981). The ocelli confer the ability to respond rapidly to a change in average light intensity, as occurs when the visual field of an ocellus dips below the horizon. They can do this even at very low levels of illumination, but they are incapable of fine spatial resolution. Functional incompatibility has led to the evolution of multiple visual systems for the control of flight.

Another example is provided by multiple circulatory mechanisms in the wings of bats (Fenton, 1983; Kallen, 1977). One system provides oxygen and nutrients and removes wastes through a fine network of capillaries that lies between the arteries and veins. In the other, veins connect directly to arteries through shunts, or anastomoses, and blood flow can be adjusted to dissipate heat. The thermoregulatory function requires the ability to rapidly move large volumes of blood into the wing and is incompatible with the more usual circulatory functions. This has led to the evolution of two systems. Other examples of multiple systems serving related but different functions could be described, such as the variety of skin cells found on the surface of the body, fat depots with specialized functions (Mrosovsky, 1986), and multiple muscle systems (Burke, 1985).

Functional incompatibility can help explain why adaptive specializations in memory seem to occur with some memory problems and not with others. Some memory problems may be so similar that they can all be effectively solved in the same way. Other problems may be insolvable except by a memory system with special features. Such special features, however, may make the system quite unsuitable for the solution of additional problems.

\section{Multiple Memory Systems in Animals}

We will turn now to specific examples of functionally incompatible memory systems in animals. We suggest, as have others, that song learning, imprinting, and orientation are based on memory systems with unique properties and thus provide support for a nonunitary view of memory. Equally important, we hope to show how these properties provide clear illustrations of the importance of functional incompatibility in the evolution of multiple memory systems. To accomplish this we will first consider in some detail the properties of song learning and then compare these with the properties of a different kind of memory, that used by food-storing birds to recover their hidden caches. 


\section{Song Learning}

Song production in birds is seasonal, occurring primarily during breeding in spring and summer. Song is used to attract mates and to defend breeding territories (Slater, 1983). In many species local dialects of song occur, and within an area individuals may have different repertoires of songs (Krebs \& Kroodsma, 1980). Both of these phenomena are the result of birds learning the songs that they sing.

Research on song learning usually proceeds by raising young birds in acoustic isolation from other birds and exposing them to the playback of different kinds of recorded song. According to Kroodsma (1982), intraspecific learning of song has been found in every oscine species that has been carefully studied. Song learning shows considerable diversity, following different rules in different species (for reviews of the topic, see Konishi, 1985; Kroodsma, 1982; Marler \& Peters, 1982; Slater, 1983). But certain unusual features that are not shared with other kinds of learning recur: (a) restrictions on what is learned, (b) a restricted period during which learning occurs, (c) separation in time of learning and performance, and (d) distinct neural structures involved in song learning. It is also possible to show that the way a bird learns the songs it sings is very different from the way it learns those songs that it does not sing but can remember and discriminate when they are sung by other birds.

Restrictions on what is learned. Some species possess a selective mechanism that excludes all but conspecific songs as candidates for vocal learning. Marler (1970) has called this the innate auditory template. Swamp sparrows (Zonotrichia georgiana), for example, will not learn the phrases of the closely related song sparrow (Zonotrichia melodia) even when these phrases are presented using the same procedures that lead to the acquisition of swamp sparrow phrases (Marler \& Peters, 1977). Similar results have been obtained with chaffinches (Fringilla coelebs; Thorpe, 1958) and white-crowned sparrows (Zonotrichia leucophrys; Marler \& Tamura, 1964). Although the action of the auditory template may sometimes be complex (Kroodsma, 1982; Marler \& Peters, 1981), it is clear that some songs are admitted to memory and others are excluded.

Timing of learning. In many species, song learning is restricted to a particular time during development. From 8 to 56 days following hatching, white-crowned sparrows will acquire the songs of models, but before and after this period they will not (Marler, 1970). More songs are learned by swamp sparrows during the period 20 to 30 days after hatching, fewer in the period 40 to 50 days following hatching, and fewest in the period 60 to 70 days after hatching (Kroodsma, 1982). In Bewick's wren (Thryomanes bewicki) very little song learning occurs beyond 60 days after hatching (Kroodsma, 1974).

Memory and song production. Swamp sparrows provide a clear example of a restricted period of song acquisition followed by a silent retention period of several months before the first production of adult song occurs about one year after hatching (Marler \& Peters, 1981). Marsh wrens show a similar pattern of retention without additional input of song and without rehearsal, at least not in the form of song production (Kroodsma \& Pickert, 1980). During the period between acquisition and first performance, songs are retained in memory with no evidence of decay, because songs are accurately reproduced with- out additional presentation of the model song. Remembered songs are used as templates to which a bird matches its song production during the breeding season.

Neural basis of song learning. Two nuclei in the avian brain, the hyperstriatum ventrale pars caudale (HVc) and the nucleus robustus archistriatalis (RA), are known to control singing in canaries (Serinus canarius; Nottebohm, Stokes, \& Leonard, 1976). These centers are responsible for song production and for the matching of song output to song types stored in memory. Remarkable variation, correlated with song output, occurs in these nuclei. The volumes of $\mathrm{HVc}$ and RA are positively correlated with the size of the song repertoire (Nottebohm, Kasparian, \& Pandazis, 1981), and both nuclei show seasonal waxing and waning in volume, correlated with the seasonal occurrence of song (Nottebohm, 1981). In HVc, these changes in volume are due to proliferation of glia and endothelial cells and, most interesting, to neurogenesis (Goldman \& Nottebohm, 1983).

Brain structures involved in the production of remembered songs can thus be identified and readily distinguished from brain structures with no effect on song production and no morphological variation correlated with song acquisition. As mentioned earlier, neural localization does not by itself imply the existence of a separate memory system, it shows only that the system can be identified neurally. The distinctive rules of operation of the song-learning system are the features that distinguish it from other memory systems.

Songs not sung. We have been describing the acquisition of songs that a bird sings. But birds also learn and remember songs that they do not sing. A number of studies have shown that territory-holding birds recognize the songs of their neighbors, even if they do not sing these songs themselves. Birds will respond more aggressively, for example, when the playback of a neighbor's song comes from an unusual direction than when the same song comes from within the neighbor's territory (Brooks \& Falls, 1975; Falls, 1982; Falls \& D'Agincourt, 1981). In great tits (Parus major), learning of neighbors' songs continues into adult life, long after the learning of songs that are sung has ended (McGregor \& Avery, 1986). Thus the restricted period for song learning that we described earlier does not occur for songs that are not sung. Songs that are not sung can be learned at any time, perhaps in a way that differs little from the way the bird learns to discriminate among stimuli of any kind (McGregor \& Avery, 1986).

\section{Imprinting and Orientation}

Song learning is not the only memory system with distinctive and unusual features. Imprinting in birds, the learning of stellar orientation cues by migratory birds, and the learning of olfactory orientation cues by salmonid fish provide further examples.

Imprinting. Imprinting describes the effects of early social experience on attachment and following of the parent by young birds newly out of the nest and also the effects of early social experience on the choice of mate at sexual maturity. These two kinds of imprinting are often called filial and sexual imprinting, respectively.

The features that distinguish imprinting from other kinds of memory resemble the unusual features of song learning. (a) 
There are restrictions on the stimuli to which imprinting will occur, though they are not so limited as is the case with song learning (Gray, 1963; Guiton, 1966; Immelmann, 1972b). (b) There is a restricted period during which imprinting occurs (Bateson, 1979; Bateson \& Reese, 1969; Gottlieb, 1961; Landsberg, 1976). (c) There is a long interval, in the case of sexual imprinting, between the time imprinting occurs and its first effects on behavior (Immelmann, 1972a, 1972b). (d) There are distinct neural structures involved in imprinting (Bateson, Rose, \& Horn, 1973; Horn, 1985). (e) In animals exhibiting imprinting, memory for other individuals can also occur by processes that do not involve imprinting (Colgan, 1983).

Stellar orientation. Migratory birds that fly at night orient to celestial cues. The stellar configuration is learned by these birds, as shown by Emlen $(1970,1972)$. Hand-reared birds that are not exposed to any celestial cues prior to the period of migration show no oriented migratory activity, whereas handreared birds exposed to artificial night skies in a planetarium show activity oriented in the correct direction with respect to these stellar cues (Emlen, 1970). Most interesting, hand-reared birds exposed to artificial night skies with an axis of rotation about the star Betelgeuse, instead of Polaris, show migratory movements that would be correctly oriented if Betelgeuse, not Polaris, was the northern pole star. Thus the pattern of celestial rotation imparts a directional significance to these cues, which are then learned and remembered by migratory birds. More recent work (Wiltschko \& Wiltschko, 1976) has shown that magnetic compass information may also impart directional significance to these learned celestial cues. The unusual aspect of memory for celestial patterns is that exposure to a pattern with an axis of rotation, any axis of rotation evidently, results in acquisition, retention, and use of the pattern to guide migratory movements, in the absence of any previous association between the pattern and oriented movement.

Olfactory orientation. Coho, sockeye, Atlantic, and spring chinook salmon return to spawn in the stream where they were born. They find the stream 1 to 5 years after they have left it by following olfactory cues that uniquely identify it. The cues are learned just before the fish leave their natal stream, at the time they transform from parr to smolts. Exposure of as little as $4 \mathrm{hr}$ to experimental olfactory cues during the smolt transformation is sufficient for the fish to home, years later, to a stream to which the cue has been added (Hasler \& Scholz, 1983). The imprinting process is under the control of the same hormones that cause the transformation from parr to smolt. Following imprinting, the fish do not orient to the learned odor cues until they come into spawning condition.

These three examples, like the more extensive discussion of song learning, are intended to show that in animals there exist cases of memory with restrictions on what is admitted to memory, restricted periods during which this can occur, or long periods of retention without additional opportunities for acquisition or rehearsal. How functional incompatibility might lead to the evolution of such memory systems is the topic of the next section.

\section{Functional Incompatibility: Song Learning and Food Caching}

Does learning to imitate songs really require a specialized memory system? Probably not. What may require a specialized memory system is the way these songs are learned and the conditions under which birds learn them. These may be the selective pressures that have led to the observed specializations in the rules for song learning.

Songs are used by males to defend their breeding territories and to attract mates and must therefore be recognizable as the songs of a particular species. Thus only some songs can be candidates for learning, and songs sung by other species must be excluded. The seasonality of song imposes another restriction. If song production is to be modeled on songs previously heard, some mechanism must bridge the gap between one breeding season and the next and preserve the song types acquired from modification or decay during this period. This requirement arises because song is rarely heard between breeding seasons.

A further restriction on the timing of song learning may occur because song dialects can indicate to which subpopulation of a species a particular individual belongs. Recognition by potential mates of local song dialects could lead birds to breed with members of the same subpopulation, thereby preventing the breakup of coadapted gene complexes. This idea is controversial, but if correct would provide an additional reason for the restricted period during which song learning occurs. Learning songs early in life, from members of the same breeding subpopulation, should ensure that the appropriate song dialect is acquired. Later song learning, for example after dispersal or during migration when subpopulations are mixed, could result in learning an inappropriate dialect.

These functions of song, and restrictions on when and how songs are learned, are probably responsible for such idiosyncratic phenomena in song learning as templates, sensitive periods, and long-term retention without modification or decay. But these specializations not only help solve the song-learning problem, they also make the song-learning system particularly unsuitable for the solution of other memory problems. We can illustrate this functional incompatibility by considering the consequences of attempting to use the song-learning system to perform some other task, such as recovering cached food (Sherry, 1985).

Birds such as marsh tits and black-capped chickadees (Parus palustris and Parus atricapillus) store food in a scattered distribution within their home range. They may store several hundred food items per day, placing one item at a time in widely separated sites. Cache sites are never reused in the wild, and the food is collected several days after it is stored. Marsh tits, chickadees, and other birds recover their stored food by remembering the precise spatial locations of their caches (Cowie, Krebs, \& Sherry, 1981; Kamil \& Balda, 1985; Sherry, 1982, 1984a; Sherry, Krebs, \& Cowie, 1981; Shettleworth \& Krebs, 1982; Vander Wall, 1982). The functional demands of this problem differ greatly from that of song learning, and attempting to solve the food-storing problem with the song-learning system reveals several serious functional incompatibilities. Restrictions on what is admitted to memory would mean that only certain classes of spatial locations could be remembered. Marsh tits and chickadees show no restrictions on what kind of spatial locations can be remembered, either within the range of natural sites used or within the variety of artificial sites used in laboratory studies (Cowie et al., 1981; Sherry, 1984a; Sherry et al., 1981; Shettleworth \& Krebs, 1982). A sensitive period would 
have the consequence that cache sites established within this period would be remembered, and caches established at other times would not. Although there is some seasonality in caching behavior (Ludescher, 1980), birds in captivity will cache at all times of year, and there is no indication that caches are relocated more accurately at some times than at others. Resistance to modification by subsequent experience would have the effect that once remembered, a cache site could not be forgotten, and birds would continue to revisit cache sites they had themselves long since emptied. Marsh tits and chickadees readily learn after one visit to avoid cache sites they have emptied themselves or discovered empty owing to theft by other animals (Sherry, 1982, 1984a). It seems clear that a number of difficulties would arise if the song-learning system was used for cache recovery. The same is true if songs were learned and remembered in the way cache sites are. A continuous turnover of song types would be possible, and there would be nothing to prevent the inclusion in the repertoire of the songs of other species, which could, furthermore, be acquired at any time during the bird's lifetime.

We do not intend to suggest by the preceding comparison that cache recovery is mediated by a specialized memory system in the way that song learning is. Memory used in cache recovery may not differ very much from memory used to solve other spatial problems, such as foraging (Sherry, 1984b, 1987a). We do intend to suggest, however, that the systems serving song learning and cache recovery have fundamentally different rules of operation and that functional incompatibility is great enough in this case to have resulted in selection for multiple memory systems.

\section{Multiple Memory Systems in Humans and Primates}

In the foregoing discussion, we presented evidence for specialized memory systems in various species of animals and showed how the properties of these systems illustrate the role of functional incompatibility. Does the idea of functional incompatibility also help us to understand learning and memory systems in humans and other primates? We now consider the relevant evidence on multiple memory systems and then discuss it in light of the concept of functional incompatibility.

A growing number of investigators in cognitive psychology, neuropsychology, and neuroscience have argued for the existence of multiple memory systems. In most cases, dichotomous classifications of memory have been advanced, such as procedural versus declarative (Cohen, 1984; Squire, 1982), semantic versus episodic (Tulving, 1972, 1983), reference versus working (Honig, 1978; Olton, Becker, \& Handelmann, 1979), semantic versus cognitive (Warrington \& Weiskrantz, 1982), habit versus memory (Hirsh, 1974, 1980; Hirsh \& Krajden, 1982; Mahut, 1985; Mishkin et al., 1984; Mishkin \& Petri, 1984), disposjtional versus representational (Thomas \& Spafford, 1984), taxon versus locale (Jacobs \& Nadel, 1985; O'Keefe \& Nadel, 1978), and early versus late (Schacter \& Moscovitch, 1984). However, distinctions among three and even more memory systems have also been put forward (e.g., Johnson, 1983; Oakley, 1983; Tulving, 1985).

Numerous kinds of experimental evidence have been cited as support for the foregoing distinctions, and we will not review the merits of all relevant data here (see Cohen, 1984; Schacter, 1985a; Schacter \& Tulving, 1982; Squire, 1982; Tulving, 1983, 1985). Instead, we shall consider briefly the distinction between memory systems that we believe has received the strongest and most widespread empirical support. We will then discuss the characteristics of the two hypothesized systems in light of the evolutionary argument that we have advanced.

\section{Memory Systems I and II}

Consistent with many of the investigators just cited, we think that a strong case can be made for a distinction between a memory system that supports gradual or incremental learning and is involved in the acquisition of habits and skills and a system that supports rapid one-trial learning and is necessary for forming memories that represent specific situations and episodes. The former system has been referred to as "procedural," "habit," "taxon," or "semantic"; the latter has been described as "declarative," "memory," "locale," or "episodic." We will not debate the merits and drawbacks of these different labels and the ideas that they represent. Instead, we will refer to the two hypothesized systems in generic terms, calling the system referred to as "habit" or "procedural" System I and the system referred to as "declarative" or "episodic" System II.

Evidence for the psychological and neurobiological reality of such a distinction between memory systems comes from studies of both humans and primates. We will consider first the results of studies with human subjects. As early as 1920 , Smith and McDougall argued for a distinction between memory and habit on the basis of experiments in which performance on tasks that required repetitive learning (e.g., learning to type) was uncorrelated with performance on tasks that tapped memory for unique episodes (e.g., recognition of once-presented pictures). Interestingly, few if any memory researchers followed up Smith and McDougall's findings, and most of the recent evidence for dissociations between memory systems has come from studies of brain-damaged amnesic patients. Amnesia occurs as a consequence of various types of neurological insult and is typically associated with damage to the medial temporal and diencephalic regions of the brain (for review, see Cermak, 1982; Hirst, 1982; Rozin, 1976b; Squire, 1982; Whitty \& Zangwill, 1977). The most striking characteristic of amnesic patients is their inability to remember recent events and to learn many types of new information, even though intelligence, perception, and language are unaffected or minimally impaired. Amnesic patients may fail to recall and recognize events after delays of seconds or minutes, both in the laboratory and in everyday life (e.g., Schacter, 1983).

Despite this severe impairment of memory functions associated with System II, a number of studies have shown that amnesic patients learn new habits and skills (System I functions) in an entirely "normal" manner. Normal learning has been observed on tasks in which learning proceeds gradually, and recollection of specific events is not required. For example, studies conducted by Milner and her colleagues in the 1960 s revealed that the densely amnesic patient H.M. could learn various motor skills, such as the pursuit rotor and mirror-tracing tasks, in a normal or near-normal manner (Milner, 1962; Milner, Corkin, \& Teuber, 1968). Strikingly, H.M. had no recollection of his learning experiences and claimed that he had never previously 
performed the various tasks on which he showed robust learning. Similar dissociations between normal or near-normal motor-skill learning and impaired memory for the experience of learning have been reported by other investigators (e.g., Brooks \& Baddeley, 1976; Cermak, Lewis, Butters, \& Goodglass, 1973; Eslinger \& Damasio, 1985; Starr \& Phillips, 1970; Talland, 1965).

Recent research with amnesic patients has also revealed normal learning of perceptual and cognitive skills. Cohen and Squire (1980) and Moscovitch, Winocur, and McLachlan (1986) used a task devised by Kolers $(1975,1976)$ in which subjects attempt to read mirror-inverted script. They found that time to read the inverted script showed a comparable decrease in both amnesics and controls, even though the amnesic patients did not consciously remember the specific items that they had read and often had no recollection for having performed the reading task. A similar pattern of results-excellent learning despite impaired remembering-has been observed on tasks involving puzzle solving (Brooks \& Baddeley, 1976), acquisition of a rule for generating numbers (Kinsbourne \& Wood, 1975), and learning to respond to a repeating sequential pattern (Nissen \& Bullemer, 1987).

As noted earlier, few studies of normal subjects have attempted to dissociate Systems I and II, but one recent experiment suggests that it is possible to produce such a dissociation in normal subjects pharmacologically. Nissen, Knopman, and Schacter (in press) examined the effects of the amnestic agent scopolamine on standard recall and recognition tests and on a task that involved learning to respond to a repeated pattern (cf. Nissen \& Bullemer, 1987). On the latter task, subjects simply press a button when one of several lights in a spatial display is illuminated. Normal subjects respond to the onset of each light faster when a sequential pattern of illumination is repeated than when the lights are illuminated randomly; learning of the pattern is gradual and develops over several trials. Nissen et al. found that subjects who had been injected with scopolamine showed a normal rate of learning on this task. However, scopolamine subjects were substantially impaired on standard memory tasks that required recall and recognition of once-presented materials.

The foregoing studies demonstrate that gradual learning of skills and habits can proceed independently of the ability to recollect specific events or episodes. A number of studies conducted with nonhuman primates converge on a similar conclusion. It has been known for some time that lesions of the hippocampus and other limbic structures do not impair the ability of monkeys to acquire object and pattern discriminations (Mishkin, 1954; Orbach, Milner, \& Rasmussen, 1960). A prominent feature of discrimination learning is that it occurs gradually, reaching asymptotic levels after numerous trials and sessions. More recent studies have shown that discrimination learning is spared in hippocampal monkeys despite severe impairments on tests of delayed matching and nonmatching to sample, which require animals to remember information specific to a single episode (Mahut, 1985; Mahut \& Moss, 1984; Malamut, Saunders, \& Mishkin, 1984; Zola-Morgan \& Squire, 1985). Significantly, normal discrimination learning in amnesic monkeys who perform poorly on delayed nonmatching to sample has been observed even when only one discrimination trial occurs in a learning session and successive learning sessions are sepa- rated by $24-\mathrm{hr}$ retention intervals (Malamut et al., 1984). The dissociation between discrimination learning and delayed nonmatching to sample performance has also been observed in a developmental study: Infant monkeys learned visual discriminations as proficiently as adult monkeys did, yet were impaired relative to adults on the delayed nonmatching task (Bachevalier \& Mishkin, 1984).

Zola-Morgan and Squire (1984), in attempting to build an animal model of human amnesia, have observed a dissociation similar to those already described. They used a motor-skill learning task in which monkeys attempted to remove a candy Lifesaver from a curved metal rod. Results indicated that monkeys with hippocampal-amygdala lesions showed normal learning on this task: The time taken to remove the Lifesaver from the rod decreased across trials by comparable amounts in normal monkeys and those with lesions. As has been found by others, however, monkeys with lesions were severely impaired on a delayed nonmatching to sample task.

Taken together, the foregoing studies provide compelling psychological evidence that gradual learning of certain habits and skills can proceed independently of the ability to remember specific episodes and also provide strong neurobiological evidence that habit or skill learning is mediated by brain structures other than the limbic structures in the medial temporal region that appear to be critical for remembering individual events. (For a similar pattern of dissociation in rats, see O'Keefe \& Nadel, 1978; Olton et al., 1979; Thomas, 1984). It is this converging evidence that has persuaded us and numerous other investigators of the necessity to postulate two different and at least partially independent memory systems. Note, however, that some evidence concerning amnesic patients may appear to be inconsistent with the System I-System II distinction. Specifically, a number of studies have demonstrated that amnesic patients show normal performance facilitations, referred to as repetition priming effects, following a single study trial. Normal priming effects in amnesic patients have been documented on tests such as word-stem completion (e.g., Graf, Squire, \& Mandler, 1984; Warrington \& Weiskrantz, 1974), tachistoscopic identification (Cermak, Talbot, Chandler, \& Wolbarst, 1985), free association (Schacter, 1985b; Shimamura \& Squire, 1984), and homophone spelling (Jacoby \& Witherspoon, 1982; for review and discussion, see Schacter \& Graf, 1986; Shimamura, 1986). Priming effects occur despite patients' inability to recall and recognize target information explicitly, and thus have properties that resemble the gradual learning phenomena attributed to System I: Both are expressed implicitly and are inaccessible to conscious recollection. Despite this similarity, however, we do not think that priming is subserved by the same process or system involved in habit/skill learning. Recent evidence has revealed that priming and skill learning can be experimentally dissociated from each other (Butters, 1987), and several other reasons for favoring this view have been discussed elsewhere (Schacter, $1985 \mathrm{~b}, 1987$ ). Priming effects may be attributable to dissociations within the general domain of System II and perhaps to processes that are not readily captured by the System I-System II dichotomy (see Schacter, 1987, for discussion).

\section{Functional Incompatibility in Memory Systems I and II}

We will now consider how observations concerning multiple memory systems in humans and other primates relate to the 
evolutionary argument that we have put forward. According to our logic, different memory systems evolve when the properties of an existing system, as shaped by environmental demands and selection pressures, are incompatible with the solution to a new environmental problem. Thus we should expect to find some basic incompatibilities between the kinds of tasks that Systems I and II are capable of handling. Analysis of the general nature of the problems handled by the two systems suggests that such incompatibilities do exist. As others have suggested (e.g., Kinsbourne \& Wood, 1975, 1982; Underwood, 1979), one of the keys to gradual learning of habits and skills is the detection and preservation of invariances across episodes. It seems reasonable to assume that an efficient habit-learning system will preserve those features of an experience that recur in different episodes and are thus crucial to the learning of a skill, and it will ignore or discard unique and idiosyncratic features of an episode that do not recur and are thus not essential to skill learning. A skilllearning system that preserved significant amounts of detail concerning temporal, spatial, and other contextual details of each episode in which learning occurred would be seriously impaired with respect to its main function: the development of smooth and eventually automatic execution of the component activities that constitute the skill, performed in response to certain invariant features of episodes. Of course, to extract the invariant features from a series of episodes, this system must initially possess fairly detailed information about these episodes. The critical point is that this detail is not retained after the invariant features have been extracted. In contrast, it would appear that the major function of the episodic-representational system is to preserve the contextual details that uniquely mark individual experiences-to preserve variance across episodes, rather than invariance. When an animal remembers the location of stored food or when and where a predator was encountered, a system is needed that can store and later provide access to a wealth of features that are uniquely characteristic of each episode. A system that specialized in the preservation of invariances would not be particularly helpful in such a situation.

What we are suggesting, then, is that preservation of the invariances and variances among experiences are mutually incompatible tasks that can be best handled-and perhaps only handled-by functionally separate systems. We think that the data demonstrating dissociations between habit-skill learning and episodic remembering indicate that evolution has in fact produced different systems to cope with these mutually incompatible problems.

The foregoing discussion focused on a single hypothesized distinction between memory systems, partly because this distinction has occupied center stage in recent discussions of multiple memory systems and partly because converging evidence can be marshalled in support of it. We do not, however, wish to imply that the validity of our evolutionary argument depends solely on the evidence for the System I versus System II distinction, nor do we wish to imply that these two systems constitute an exhaustive list of dissociable memory systems. At least two other possibilities for specialized memory systems have received some empirical support and thus merit brief mention. First, both cognitive and neuropsychological data suggest that immediate, or primary, memory, which holds information for brief temporal intervals (i.e., seconds), may be a neurophysio- logically and functionally distinct memory system (Shallice, 1979; Warrington, 1982). Second, several developmental psychologists and psycholinguists have argued on empirical and theoretical grounds that language learning may be handled by a specialized system (e.g., Krashen, 1975; Lenneberg, 1967). Further theoretical and conceptual analysis of each of these candidate systems could be profitably pursued within the context of the evolutionary argument that we have advanced.

\section{Exaptation and Generality in Memory Systems}

At the outset we suggested that an evolutionary analysis allows for generality as well as specificity in memory and learning. The preceding discussions of adaptive specialization and functional incompatibility focused on the specific features of different memory systems. We will now consider the concept of exaptation, which is critical to an understanding of the general features common to many memory systems.

It has long been recognized that not all the effects of a structure or behavior can be regarded as adaptations (Williams, 1966). Some will be effects in which selection has played no role. Williams (1966) provided the illustration of the behavior of a hypothetical fox in winter that follows its previous path through the snow whenever it can. This would probably make traveling through snow easier, and the behavior could well be an adaptation to an environment where snow is common. But it would clearly be incorrect to regard the feet of foxes as adaptations for making paths in snow. Traits and structures can have many effects on the environment in addition to the function for which they have been shaped by natural selection. Some of these effects, like paths in the snow, may be the incidental consequences of genuine adaptations. Other effects that are not adaptations can arise from pleiotropy, genetic linkage, or allometric relations among structures (Gould \& Lewontin, 1979).

These effects may nonetheless influence survival and reproductive success, and to distinguish such effects from adaptations produced by direct selection, Gould and Vrba (1982) have labeled them exaptations. Their coining of the term is an attempt to distinguish two usages of the word adaptation. One is that used by Williams (1966): a trait shaped by natural selection to perform a particular function. The other is a broader sense, as used by Bock and others (Bock, 1980; Bock \& Von Wahlert, 1965): any trait that has some effect on survival and reproduction.

Exaptations can of course provide raw material on which natural selection can act. These raw materials are often called preadaptations (Bock, 1959; Mayr, 1960). Although the term preadaptation, when used correctly, avoids the error of supposing that traits can be selected in order to provide precursors for later selection, calling the raw material exaptations avoids this problem entirely. The evolution of feathers provides a good example of exaptation (Gould \& Vrba, 1982). Whatever the original function of feathers, they cannot have been of much use for flight. Thermoregulation seems a probable initial function, though others, including prey capture, have been suggested (Ostrom, 1974). After some selection for thermoregulatory function had occurred, however, feathers may have begun to have effects on locomotion in some feathered dinosaurs of the Jurassic period. Such effects would be exaptations, but the beginning 
of selection of feathers as adaptations for flight. Modification of an exaptation may thus lead to an important adaptation.

The importance of the idea of exaptation to a discussion of the evolution of memory is that few of the current functions memory serves can be genuine adaptations of memory. Human memory is clearly not an adaptation for remembering telephone numbers, though it performs this function fairly well, nor is it an adaptation for learning to drive a car, though it handles this rather different problem effectively, too. The idea of exaptation emphasizes the difference between the current functions memory systems perform and their evolutionary histories. Thus an adaptive specialization of memory for solving a particular environmental problem need not have arisen through a gradual process, each intermediate step itself having some selective advantage in solving this problem, as Rozin and Kalat (1971) envisioned. Instead, it may arise as an exaptation within an existing memory system or its components.

We suggest that by virtue of evolutionary exaptation, memory systems that evolve initially as solutions to one environmental problem may come to serve many other functions. Exaptation may not be the only means whereby specialized processes come to serve general functions. Rozin (1976a) has provided a somewhat different evolutionary account of how specialized systems may acquire additional functions. Nonetheless, because of the process of exaptive generalization, some memory systems may eventually serve as general purpose systems that handle a large variety of problems. This observation enables us, at least in part, to accommodate the views of theorists who have argued that memory and learning are subject to a single set of general laws (e.g., Bitterman, 1975; Revusky, 1977) or, similarly, have argued in favor of a continuum of memory processes and have rejected the idea of dissociable memory systems (Craik, 1983; Jacoby, 1984). Evolution has indeed produced some memory and learning systems that operate across many domains and therefore may be described parsimoniously with a single set of explanatory principles. If our analysis is correct, however, the evolutionary process has done more than this: It has also yielded some specialized systems that require different explanatory principles. Thus, in our view, the notions of general laws of learning and a unitary memory system are not so much incorrect as incomplete. The same would apply to the extreme view that all memory functions originate as adaptive specializations (Lockard, 1971) and require separate explanatory principles. An evolutionary analysis indicates that both generality and specificity must be expected to occur as characteristics of memory and learning.

\section{Concluding Comments}

This article has outlined an evolutionary scenario for the emergence of multiple memory systems and has brought together evidence and ideas from human and animal neuropsychology on the one hand and from ethological investigations of animal behavior on the other. To conclude, we shall delineate some implications of our position for several issues in the contemporary study of learning and memory.

A large number of investigators in neuropsychology, cognitive psychology, and neuroscience have proposed different distinctions between various memory systems. Our evolutionary analysis, though broadly based and consistent with claims for multiple memory systems, does not, of course, imply that each proposed distinction is useful or valid. It is beyond the scope of this article to evaluate the strengths and weaknesses of all proposed distinctions between memory systems, but it is important to emphasize that an evolutionary stance does not logically provide support for every existing distinction. Similarly, our position does not imply that memory theorists should freely postulate new memory systems whenever experimental evidence indicates that performance on different types of memory tasks can be dissociated. Several investigators have expressed concern about the possibility of an undesirable proliferation of proposed memory systems (e.g., Craik, 1983; Jacoby, 1983; Roediger, 1984; Schacter \& Tulving, 1982; Sherry, 1984b), a concern that we believe is legitimate. Our analysis actually leads to a somewhat conservative position concerning the postulation of different memory systems in humans and other animals. We propose that distinct memory systems evolve only when there is functional incompatibility between the properties of an existing system and the demands posed by a novel environmental problem. Therefore, we would be hesitant to postulate a new memory system to accommodate a particular experimental finding or pattern of findings unless a good case could be made that the proposed system performs a function that cannot be performed by another memory system.

This latter observation suggests a more general role for an evolutionary perspective in current debates about multiple memory systems: It can serve as a possible source of guidance for evaluating evidence concerning a proposed distinction. As noted elsewhere (e.g., Roediger, 1984; Schacter, 1984; Sherry, 1987b; Tulving, 1983), there are no entirely satisfactory criteria for determining whether experimentally observed dissociations among memory tasks support a distinction between memory systems or should be interpreted as evidence for different processes operating within the same system. Analysis of whether the functions served by the two hypothesized memory systems are mutually incompatible could be helpful when such interpretive problems arise. The idea of functional incompatibility is an attempt to encourage those who postulate the existence of multiple memory systems to consider not only the evidence from dissociation experiments, neurological damage, and the unusual capacities of some animals but also the supposed functions of the postulated systems. Questions about the functions of memory can be used along with questions about causal mechanisms to evaluate specific proposals about multiple memory systems.

It would also be desirable to provide a formal test for the occurrence of functional incompatibility-a well-specified set of criteria for determining when the functional demands of different memory tasks are incompatible. Unfortunately, we cannot do so now because the necessary information concerning the operation of memory is unavailable. To provide a convincing analysis of functional incompatibility, it would be necessary to possess (a) an understanding of the demands of a particular memory problem, (b) a description of the architecture of the hypothesized system that allegedly handles the problem, and (c) a description of the properties of some other hypothesized system that allegedly cannot handle the problem. With the benefit of this information, it would be possible to specify 
why compatibility exists for one system and incompatibility for another.

To illustrate how analysis of functional incompatibility can proceed when sufficient information is available about the properties of proposed systems, we must return to our example of blood supply in the wings of bats. Here, the system that supplies oxygen to the metabolically active tissues of the wing consists of capillary beds of such small diameter that erythrocytes pass along them in single file (Kallen, 1977). The delivery of oxygen is well served by this system. But use of blood circulation to dissipate heat requires a completely different arrangement. Anastomoses between major arteries and veins bypass the capillary beds and allow substantial volumes of blood to flow more quickly past the wing surfaces. Heat loss by radiation, convection, or the evaporation of water from the wing surface all depend on the temperature of the surface. The warmer it is, the more heat is lost. This requires that much larger volumes of warm blood be delivered than can be achieved by the slow march of erythrocytes through narrow capillaries and is thus the source of the functional incompatibility. Because a detailed structural description of the systems is available, it is a relatively straightforward matter to pinpoint the functional incompatibilities.

We do not want to suggest, of course, that analysis of functional incompatibility can only be undertaken after analysis of structural properties is complete. Analysis of functional incompatibility would then be no more than a postscript to mechanistic understanding, and our arguments for the usefulness of functional incompatibility would be dangerously circular. Rather, we are suggesting that hypotheses regarding alleged memory systems must specify properties of the proposed systems in sufficient detail to allow a meaningful analysis of functional incompatibilities. Unfortunately, such detailed architectural descriptions are rarely available at the current stage of memory research. The point of the bat wing example is that in wellunderstood biological systems, functional incompatibilities can be shown to exist, and we have no reason to believe that memory is an exception.

How, then, can the idea of functional incompatibility help advance our understanding of memory systems? We envisage a kind of boot-strapping operation in which awareness of functional considerations can help form and refine hypotheses about memory processes and systems. In turn, as understanding of mechanism increases, it should be possible to specify more clearly the range of functions that a system can serve and, hence, set the stage for meaningful analyses of functional incompatibilities. Though students of memory and learning have traditionally focused on the mechanisms of memory, they have too often neglected to consider what functions are served by memory or memory systems (cf. Bruce, 1985; Neisser, 1976; Olton, 1984; Rozin \& Kalat, 1971; Rozin \& Schull, in press; Shettleworth, $1983,1985)$. Evolution provides a context in which consideration of function can contribute to the analysis of memory.

\section{References}

Bachevalier, J., \& Mishkin, M. (1984). An early and a late developing system for learning and retention in infant monkeys. Behavioral Neuroscience, $98,770-778$.
Barnard, C. J., \& Burk, T. (1979). Dominance hierarchies and the evolution of "individual recognition." Journal of Theoretical Biology, 81 . $65-73$.

Bateson, P. (1979). How do sensitive periods arise and what are they for? Animal Behaviour, 27, 470-486.

Bateson, P. P. G., \& Reese, E. P. (1969). The reinforcing properties of conspicuous stimuli in the imprinting situation. Animal Behaviour, I7, 692-699.

Bateson, P. P. G., Rose, S. P. R., \& Horn, G. (1973). Imprinting: Lasting effects on uracil incorporation into chick brain. Science, 181, 576578.

Bentley, D. (1976). Genetic analysis of the nervous system. In J. C. Fentress (Ed.), Simpler networks and behavior (pp. 126-139). Sunderland, MA: Sinauer.

Bitterman, M. E. (1975). The comparative analysis of learning. Science, $188,699-709$.

Bock, W. J. (1959). Preadaptation and multiple evolutionary pathways. Evolution, 13, 194-211.

Bock, W. J. (1980). The definition and recognition of biological adaptation. American Zoologist, 20, 217-227.

Bock, W. J., \& Von Wahlert, G. (1965). Adaptation and the form-function complex. Evolution, 19, 269-299.

Bolles, R. C. (1970). Species-specific defense reactions and avoidance learning. Psychological Review, 77, 32-48.

Brooks, D. N., \& Baddeley, A. D. (1976). What can amnesic patients learn? Neuropsychologia, 14,111-122.

Brooks, R. J., \& Falls, J. B. (1975). Individual recognition by song in white-throated sparrows. I. Discrimination of songs of neighbours and strangers. Canadian Journal of Zoology, 53, 879-888.

Bruce, D. (1985). The how and why of ecological memory. Journal of Experimental Psychology: General, 114, 78-90.

Burke, R. E. (1985). Integration of sensory information and motor commands in the spinal cord. In P. Stein (Ed.), Motor control: From movement trajectories to neural mechanisms (Society for Neuroscience Short Course Syllabus, pp. 44-65). Washington, DC: Society for Neuroscience.

Burnet, B., \& Connolly, K. J. (1981). Gene action and the analysis of behaviour. British Medical Bulletin, 37, 107-113.

Butters, N. (1987, February). Procedural learning in dementia: A double dissociation between Alzheimer and Huntington's disease patients on verbal priming and motor skill learning. Paper presented at the meeting of the International Neuropsychological Society, Washington, DC.

Caraco, T. (1981). Energy budgets, risk and foraging preferences in dark-eyed juncos (Junco hyemalis). Behavioral Ecology \& Sociobiology. 8, 213-217.

Cermak, L. S. (Ed.). (1982). Human memory and amnesia. Hillsdale, NJ: Erlbaum.

Cermak, L. S., Lewis, R., Butters, N., \& Goodglass, H. (1973). Role of verbal mediation in performance of motor tasks by Korsakoff patients. Perceptual \& Motor Skills, 37, 259-262.

Cermak, L. S., Talbot, N., Chandler, K., \& Wolbarst, L. R. (1985). The perceptual priming phenomenon in amnesia. Neuropsychologia, 23, 615-622.

Chapman, R. F. (1982). The insects: Structure and function. London: Hodder and Stoughton.

Cohen, N. J. (1984). Preserved learning capacity in amnesia: Evidence for multiple memory systems. In L. R. Squire \& N. Butters (Eds.), Neuropsychology of memory (pp. 83-103). New York: Guilford Press.

Cohen, N. J., \& Squire, L. R. (1980). Preserved learning and retention of pattern-analyzing skill in amnesia: Dissociation of knowing how and knowing that. Science, 210, 207-209.

Colgan, P. (1983). Comparative social recognition. New York: WileyInterscience. 
Cowie, R. J., Krebs, J. R., \& Sherry, D. F. (1981). Food storing by marsh tits. Animal Behaviour, 29, 1252-1259.

Craik, F. I. M. (1983). On the transfer of information from temporary to permanent memory. Philosophical Transactions of the Royal Society of London, 302, 341-359.

Curio, E., Ernst, U., \& Vieth, W. (1978a). The adaptive significance of avian mobbing. II. Cultural transmission of enemy recognition in blackbirds: Effectiveness and some constraints. Zeilschrift für Tierpsychologie, 48, 184-202.

Curio, E., Ernst, U., \& Vieth, W. (1978b). Cultural transmission of enemy recognition: One function of mobbing. Science, 202, 899-901.

Darwin, C. (1859). On the origin of species. London: John Murray.

Dudai, Y. (1979). Behavioral plasticity in a Drosophila mutant, dunce ${ }^{\mathrm{DB276}}$. Journal of Comparative Physiology A, 130, 271-275.

Dudai, Y., Jan, Y.-N., Byers, D., Quinn, W. G., \& Benzer, S. (1976). dunce, a mutant of Drosophila deficient in learning. Proceedings of the National Academy of Sciences, 73, 1684-1688.

Emlen, S. T. (1970). Celestial rotation: Its importance in the development of migratory orientation. Science, 170, 1198-1201.

Emlen, S. T. (1972). The ontogenetic development of orientation capabilities. In S. R. Galler, K. Schmidt-Koenig, G. J. Jacobs, \& R. E. Belleville (Eds.), Animal orientation and navigation (NASA SP-262, pp. 191-210). Washington, DC: U.S. Government Printing Office.

Eslinger, P. J., \& Damasio, A. R. (1985). Severe disturbance of higher cognition after bilateral frontal lobe ablation: Patient EVR. Neurology, 35, 1731-1741.

Falls, J. B. (1982). Individual recognition by sounds in birds. In D. E. Kroodsma, E. H. Miller, \& H. Ouellet (Eds.), Acoustic communication in birds (Vol. 2, pp. 237-278). New York: Academic Press.

Falls, J. B., \& D'Agincourt, L. G. (1981). A comparison of neighbourstranger discrimination in eastern and western meadowlarks. Canadian Journal of Zoology, 59, 2380-2385.

Fenton, M. B. (1983). Just bats. Toronto, Ontario, Canada: University of Toronto Press.

Fodor, J. A. (1983). The modularity of mind. Cambridge: MIT Press.

Futuyma, D. J. (1986). Evolutionary biology (2nd ed.). Sunderland, MA: Sinauer.

Garcia, J., Ervin, F. R., \& Koelling, R. A. (1966). Learning with prolonged delay of reinforcement. Psychonomic Science, 5, 121-122.

Garcia, J., Hankins, W. G., \& Rusiniak, K. W. (1974). Behavioral regulation of the milieu interne in man and rat. Science, 185, 824-831.

Garcia, J., \& Koelling, R. A. (1966). Relation of cue to consequence in avoidance learning. Psychonomic Science, 4, 123-124.

Gazzaniga, M. (1985). The social brain. New York: Basic Books.

Goldman, S. A., \& Nottebohm, F. (1983). Neuronal production, migration, and differentiation in a vocal control nucleus of the adult female canary brain. Proceedings of the National Academy of Sciences, 80, 2390-2394.

Gottlieb, G. (1961). Developmental age as a baseline for determination of the critical period in imprinting. Journal of Comparative and Physiological Psychology, 54, 422-427.

Gould, S. J., \& Lewontin, R. C. (1979). The spandrels of San Marco and the Panglossian paradigm: A critique of the adaptationist programme. Royal Society of London. Proceedings B, 205, 581-598.

Gould, S. J., \& Vrba, E. S. (1982). Exaptation-A missing term in the science of form. Paleobiology, 8, 4-15.

Graf, P., Squire, L. R., \& Mandler, G. (1984). The information that amnesic patients do not forget. Journal of Experimental Psychology: Learning, Memory, and Cognition, 10, 164-178.

Gray, P. H. (1963). The descriptive study of imprinting in birds from 1873-1953. Journal of General Psychology, 68, 333-346.

Guiton, P. (1966). Early experience and sexual object-choice in the brown leghorn. Animal Behaviour, 14, 534-538.
Hamilton, W. D. (1964). The genetical evolution of social behaviour. 1 \& II. Journal of Theoretical Biology, 7, 1-52.

Hasler, A. D., \& Scholz, A. T. (1983). Olfactory imprinting and homing in salmon. Berlin, West Germany: Springer-Verlag.

Hinde, R. A. (1973). Constraints on learning: An introduction to the problems. In R. A. Hinde \& J. Stevenson-Hinde (Eds.), Constraints on learning (pp. 1-19). London: Academic Press.

Hirsh, R. (1974). The hippocampus and contextual retrieval of information from memory. Behavioral Biology, 12, 421-444.

Hirsh, R. (1980). The hippocampus, conditional operations, and cognition. Physiological Psychology, 8, 175-182.

Hirsh, R., \& Krajden, J. (1982). The hippocampus and the expression of knowledge. In R. L. Isaacson \& N. E. Spear (Eds.), The expression of knowledge (pp. 213-241). New York: Plenum Press.

Hirst, W. (1982). The amnesic syndrome: Descriptions and explanations. Psychological Bulletin, 91, 435-462.

Hollis, K. L. (1982). Pavlovian conditioning of signal-centered action patterns and autonomic behavior: A biological analysis of function. Advances in the Study of Behaviour, 12, 1-64.

Hollis, K. L. (1984). The biological function of Pavlovian conditioning: The best defence is a good offence. Journal of Experimental Psychology: Animal Behavior Processes, 10, 413-425.

Holmes, W. G., \& Sherman, P. W. (1983). Kin recognition in animals. American Scientist, 71, 46-55.

Honig, W. K. (1978). Studies of working memory in the pigeon. In S. H. Hulse, H. Fowler, \& W. K. Honig (Eds.), Cognitive processes in animal behaviour (pp. 211-248). Hillsdale, NJ: Erlbaum.

Horn, G. (1985). Memory, imprinting, and the brain. Oxford, England: Clarendon Press.

Immelmann, K. (1972a). The influence of early experience upon the development of social behaviour in estrildine finches. Proceedings of the XVth International Ornithological Congress Den Haag, 1970, 291-313.

Immelmann, K. (1972b). Sexual and other long-term aspects of imprinting in birds and other species. Advances in the Study of Behavior, 4, 147-174.

Jacobs, W. J., \& Nadel, L. (1985). Stress induced recovery of fears and phobias. Psychological Review, 92, 512-531.

Jacoby, L. L. (1983). Perceptual enhancement: Persistent effects of an experience. Journal of Experimental Psychology: Learning. Memory, and Cognition, 9, 21-38.

Jacoby, L. L. (1984). Incidental versus intentional retrieval: Remembering and awareness as separate issues. In $\mathrm{L}$. R. Squire \& N. Butters (Eds.), Neuropsychology of memory (pp. 145-156). New York: Guilford Press.

Jacoby, L. L., \& Witherspoon, D. (1982). Remembering without awareness. Canadian Journal of Psychology, 36, 300-324.

Johnson, M. (1983). A multiple-entry, modular memory system. In G. H. Bower (Ed.), The psychology of learning and motivation (Vol. 17, pp. 81-123). New York: Academic Press.

Johnston, T. D. (1981). Contrasting approaches to a theory of learning. Behavioral and Brain Sciences, 4, 125-173.

Kallen, F. C. (1977). The cardiovascular system of bats: Structure and function. In W. A. Wimsatt (Ed.), Biology of bats (Vol. 3, pp. 289 483). New York: Academic Press.

Kamil, A. C., \& Balda, R. P. (1985). Cache recovery and spatial memory in Clark's nutcrackers (Nucifraga columbiana). Journal of Experimental Psychology: Animal Behavior Processes, 11, 95-111.

Kinsbourne, M., \& Wood, F. (1975). Short-term memory and the amnesic syndrome. In D. D. Deutsch \& J. A. Deutsch (Eds.), Short-term memory (pp. 258-291). New York: Academic Press.

Kinsbourne, M., \& Wood, F. (1982). Theoretical considerations regarding the episodic-semantic memory distinction. In L. S. Cermak 
(Ed.), Human memory and amnesia (pp. 195-217). Hillsdale, NJ: Erlbaum.

Kolers, P. A. (1975). Memorial consequences of automatized encoding. Journal of Experimental Psychology: Human Learning and Memory. 1, 689-701.

Kolers, P. A. (1976). Reading a year later. Journal of Experimental Psychology: Human Learning and Memory, 2, 554-565.

Kolers, P. A., \& Roediger, H. L. III. (1984). Procedures of mind. Journal of Verbal Learning and Verbal Behavior, 23, 425-449.

Konishi, M. (1985). Birdsong: From behavior to neuron. Annual Review of Neuroscience, $8,125-170$.

Krashen, S. D. (1975). The critical period for language acquisition and its possible bases. Annals of the New York Academy of Sciences, 263, $211-224$.

Krebs, J. R., \& Kroodsma, D. E. (1980). Repertoires and geographical variation in bird song. Advances in the Study of Behaviour, 11, 143177.

Krebs, J. R., Stephens, D. W., \& Sutherland, W. J. (1983), Perspectives in optimal foraging. In A. H. Brush \& G. A. Clark, Jr. (Eds.), Perspectives in ornithology (pp. 165-216). New York: Cambridge University Press.

Kroodsma, D. E. (1974). Song learning, dialects, and dispersal in Bewick's wren. Zeitschrift für Tierpsychologie, 35, 352-380.

Kroodsma, D. E. (1982). Learning and the ontogeny of sound signals in birds. In D. E. Kroodsma, E. H. Miller, \& H. Ouellet (Eds.), Acoustic communication in birds (Vol. 2, pp. 1-23). New York: Academic Press.

Kroodsma, D. E., \& Pickert, R. (1980). Environmentally dependent sensitive periods for avian vocal learning. Nature, 288, 477-479.

Landsberg, 1.-W. (1976). Posthatch age and developmental age as a baseline for determination of the sensitive period for imprinting. Journal of Comparative and Physiological Psychology, 90, 47-52.

Lenneberg, E. (1967). Biological foundations of language. New York: Wiley.

Lewontin, R. C. (1978). Adaptation. Scientific American, 239, 212230.

Lockard, R. B. (1971). Reflections on the fall of comparative psychology. American Psychologist, 26, 168-179.

Logue, A. W. (1979). Taste aversion and the generality of the laws of learning. Psychological Bulletin, 86, 276-296.

Ludescher, F.-B. (1980). Fressen und Verstecken von Sämereien bei der Wiedenmeise Parus montanus im Jahresverlauf unter konstanten Ernährungsbedingungen [Feeding and caching of seeds in willow tits Parus montanus in the course of the year under constant feeding conditions]. Okologie der Vögel, 2, 135-144.

MacPhail, E. M. (1982). Brain and intelligence in vertebrates. Oxford, England: Clarendon Press.

Mahut, H. (1985). Dissociation of two behavioral functions in the monkey after early hippocampal ablations. In B. E. Will, P. Schmitt, \& J. C. Dalrymple-Alford (Eds.), Brain plasticity, learning, and memory (pp. 353-362). New York: Plenum Press.

Mahut, H., \& Moss, M. (1984). Consolidation of memory: The hippocampus revisited. In L. R. Squire \& N. Butters (Eds.), Neuropsychology of memory (pp. 297-315). New York: Guilford Press.

Malamut, B. L., Saunders, R. C., \& Mishkin, M. (1984). Monkeys with combined amygdalo-hippocampal lesions succeed in object discrimination learning despite 24-hour intertrial intervals. Behavioral Neuroscience, 98, 759-769.

Marler, P. (1970). Birdsong and speech development: Could there be parallels? American Scientist, 58, 669-673.

Marler, P., \& Peters, S. (1977). Selective vocal learning in a sparrow. Science, 198, 519-521.

Marler, P., \& Peters, S. (1981). Sparrows learn adult song and more from memory. Science, 213, 780-782.
Marler, P., \& Peters, S. (1982). Subsong and plastic song: Their role in the vocal learning process. In D. E. Kroodsma, E. H. Miller, \& H. Ouellet (Eds.), Acoustic communication in birds (Vol. 2, pp. 25-50). New York: Academic Press.

Marler, P., \& Tamura, M. (1964). Culturally transmitted patterns of vocal behavior in sparrows. Science, 146, 1483-1486.

Marshall, J. C. (1984). Multiple perspectives on modularity. Cognition. 17, 209-242.

Mayr, E. (1960). The emergence of evolutionary novelties. In S. Tax (Ed.), Evolution after Darwin (Vol. 1, pp. 349-380). Chicago: University of Chicago Press.

Mayr, E. (1983). How to carry out the adaptationist program? American Naturalist, 121, 324-334.

MoGregor, P. K., \& Avery, M. I. (1986). The unsung songs of great tits (Parus major): Learning neighbours' songs for discrimination. Behavioral Ecology \& Sociobiology, 18, 311-316.

Milner, B. (1962). Les troubles de la mémoire accompagnant des lésions hippocampiques bilatérales [Disorders of memory accompanying bilateral hippocampal lesions]. In P. Passovant (Ed.), Physiologie de l'hippocampe (pp. 257-272). Paris: Centre National de la Recherche Scientifique.

Milner, B., Corkin, S., \& Teuber, H. L. (1968). Further analysis of the hippocampal amnesic syndrome: 14 year follow-up study of H.M. Neuropsychologia, 6, 215-234.

Mishkin, M. (1954). Visual discrimination performance following partial ablations of the temporal lobe: II. Ventral surface vs. hippocampus. Journal of Comparative and Physiological Psychology, 47, 187193.

Mishkin, M., Malamut, B., \& Bachevalier, J. (1984). Memories and habits: Two neural systems. In J. L. McGaugh, G. Lynch, \& N. M. Weinberger (Eds.), Neurobiology of learning and memory (pp. 6577). New York: Guilford Press.

Mishkin, M., \& Petri, H. L. (1984). Memories and habits: Some implications for the analysis of learning and retention. In L. R. Squire \& N. Butters (Eds.), Neuropsychology of memory (pp. 287-296). New York: Guilford Press.

Moscovitch, M., Winocur, G., \& McLachlan, D. (1986). Memory as assessed by recognition and reading time in normal and memoryimpaired people with Alzheimer's disease and other neurological disorders. Journal of Experimental Psychology: General, 115, 331-347.

Mrosovsky, N. (1986). Body fat: What is regulated? Physiology and Behavior, 38, 407-414.

Neisser, U. (1976). Cognition and reality: Principles and implications of cognitive psychology. San Francisco: Freeman.

Neisser, U. (1987). A sense of where you are: Functions of the spatial module. In P. Ellen \& C. Thinus-Blanc (Eds.), Spatial orientation in animals and man (Vol. 2, 293-310). Dordrecht, the Netherlands: Martinus Nijhoff.

Nissen, M. J., \& Bullemer, P. (1987). Attentional requirements of learning: Evidence from performance measures. Cognitive Psychology: 19. $1-32$.

Nissen, M. J., Knopman, D. S., \& Schacter, D. L. (in press). Neurochemical dissociation of memory systems. Neurology.

Northcutt, R. G. (1984). The evolution of the vertebrate central nervous system: Patterns and processes. American Zoologist, 24, 701716.

Nottebohm, F. (1981). A brain for all seasons: Cyclical anatomical changes in song control nuclei of the canary brain. Science, 214, 1368-1370.

Nottebohm, F., Kasparian, S., \& Pandazis, C. (1981). Brain space for a learned task. Brain Research, 213, 99-109.

Nottebohm, F., Stokes, T. M., \& Leonard, C. M. (1976). Central control of song in the canary Serinus canarius. Journal of Comparative Neurology, $165,457-486$. 
Oakley, D. A. (1983). The varieties of memory: A phylogenetic approach. In A. Mayes (Ed.), Memory in animals and humans (pp. 2082). Cambridge, England: Van Nostrand Reinhold.

O'Keefe, J., \& Nadel, L. (1978). The hippocampus as a cognitive map. Oxford, England: Clarendon Press.

Olton, D. S. (1984). Comparative analysis of episodic memory. The Behavioral and Brain Sciences, 7, 250-251.

Olton, D. S., Becker, J. T., \& Handelmann, G. E. (1979). Hippocampus, space, and memory. Behavioral and Brain Sciences, 2, 313-365.

Orbach, J., Milner, B., \& Rasmussen, T. (1960). Learning and retention in monkeys after amygdala-hippocampus resection. Archives of Neurology, 3, 230-251.

Ostrom, J. H. (1974). Archaeoptryx and the origin of flight. Quarterly Review of Biology, 49, 27-47.

Packer, C. (1977). Reciprocal altruism in Papio anubis. Nature, 265, 441-443.

Pyke, G. H., Pulliam, H. R., \& Charnoy, E. L. (1977). Optimal foraging: A selective review of theory and tests. Quarterly Review of Biology, 52,137-154.

Quinn, W. G., \& Gould, J. L. (1979). Nerves and genes. Nature, 278, 19-23.

Quinn, W. G., \& Greenspan, R. J. (1984). Learning and courtship in Drosophila: Two stories with mutants. Annual Review of Neuroscience, 7, 67-93.

Quinn, W. G., Sziber, P. P., \& Booker, R. (1979). The Drosophila memory mutant amnesiac. Nature, 277, 212-214.

Revusky, S. H. (1977). Learning as a general process with an emphasis on data from feeding experiments. In N. W. Milgram, L. Krames, \& T. M. Alloway (Eds.), Food aversion learning (pp. 1-51). New York: Plenum Press.

Roediger, H. L. III (1984). Does current evidence from dissociation experiments favor the episodic/semantic distinction? Behavioral and Brain Sciences, 7, 252-254.

Roffler-Tarlov, S., \& Graybiel, A. M. (1984). Weaver mutation has differential effects on the dopamine-containing innervation of the limbic and nonlimbic striatum. Nature, 307, 62-66.

Roper, T. J. (1983). Learning as a biological phenomenon. In T. R. Halliday \& P. J. B. Slater (Eds.), Genes, development and learning (pp. 178-212). Oxford, England: Blackwell.

Rozin, P. (1976a). The evolution of intelligence and access to the cognitive unconscious. Progress in Psychobiology and Physiological Psychology, 6, 245-280.

Rozin, P. (1976b). The psychobiological approach to human memory. In M. R. Rosenzweig \& E. L. Bennett (Eds.), Neural mechanisms of learning and memory (pp. 3-48). Cambridge: MIT Press.

Rozin, P., \& Kalat, J. W. (1971). Specific hungers and poison avoidance as adaptive specializations of learning. Psychological Review, 78. $459-486$.

Rozin, P., \& Schull, J. (in press). The adaptive-evolutionary point of view in experimental psychology. In R. C. Atkinson, R. J. Herrnstein, G. Lindzey, \& R. D. Luce (Eds.), Handbook of experimental psychology. New York: Wiley-Interscience.

Schacter, D. L. (1983). Amnesia observed: Remembering and forgetting in a natural environment. Journal of Abnormal Psychology, 92, 236242.

Schacter, D. L. (1984). Toward the multidisciplinary study of memory: Ontogeny, phylogeny and pathology of memory systems. In L. R. Squire \& N. Butters (Eds.), Neuropsychology of memory (pp. 13-24). New York: Guilford Press.

Schacter, D. L. (1985a). Multiple forms of memory in humans and animals. In N. W. Weinberger, J. L. McGaugh, \& G. Lynch (Eds.), Memory systems of the brain: Animal and human cognitive processes (pp. 351-379). New York: Guilford Press.

Schacter, D. L. (1985b). Priming of old and new knowledge in amnesic patients and normal subjects. Annals of the New York Academy of Sciences, 444, 41-53.

Schacter, D. L. (1987). Implicit memory: History and current status. Journal of Experimental Psychology: Learning, Memory, and Cognition, 13, 501-518.

Schacter, D. L., \& Graf, P. (1986). Preserved learning in amnesic patients: Perspectives from research on direct priming. Journal of Clinical and Experimental Neuropsychology, 8, 727-743.

Schacter, D. L., \& Moscovitch, M. (1984). Infants, amnesics, and dissociable memory systems. In M. Moscovitch (Ed.), Infant memory (pp. 173-216). New York: Plenum Press.

Schacter, D. L., \& Tulving, E. (1982). Memory, amnesia, and the episodic/semantic distinction. In R. L. Isaacson \& N. E. Spear (Eds.), The expression of knowledge (pp. 33-65). New York: Plenum Press.

Seligman, M. E. P. (1970). On the generality of the laws of learning. Psychological Review, 77, 406-418.

Shallice, T. (1979). Neuropsychological research and the fractionation of memory systems. In L.-G. Nilsson (Ed.), Perspectives on memory research (pp. 257-277). Hillsdale, NJ: Erlbaum.

Shallice, T. (1981). Neurological impairment of cognitive processes. British Medical Bulletin, 37, 187-192.

Sherry, D. F. (1982). Food storage, memory, and marsh tits. Animal Behaviour, 30, 631-633.

Sherry, D. F. (1984a). Food storage by black-capped chickadees: Memory for the location and contents of caches. Animal Behaviour, 32, 451-464.

Sherry, D. F. (1984b). What food-storing birds remember. Canadian Journal of Psychology, 38, 304-321.

Sherry, D. F. (1985). Food storage by birds and mammals. Advances in the Study of Behavior, 15, 153-188.

Sherry, D. F. (1987a). Foraging for stored food. In M. L. Commons, A. Kacelnik, \& S. J. Shettleworth (Eds.), Quantitative analysis of behavior, VI: Foraging (pp. 209-227). Hillsdale, NJ: Erlbaum.

Sherry, D. F. (1987b). Learning and adaptation in food-storing birds. In R. C. Bolles \& M. D. Beecher (Eds.), Evolution and learning. (pp. 79-95) Hillsdale, NJ: Erlbaum.

Sherry, D. F., Krebs, J. R., \& Cowie, R. J. (1981). Memory for the location of stored food in marsh tits. Animal Behaviour, 29, 1260-1266.

Shettleworth, S. J. (1972). Constraints on learning. Advances in the Study of Behavior, 4, 1-68.

Shettleworth, S. J. (1983). Function and mechanism in learning. In M. D. Zeiler \& P. Harzem (Eds.), Advances in the analysis of behavior (Vol. 3, pp. 1-39). New York: Wiley.

Shettleworth, S. J. (1985). Food storing by birds: Implications for comparative studies of memory. In N. W. Weinberger, J. L. McGaugh, \& G. Lynch (Eds.), Memory systems of the brain: Animal and human cognitive processes (pp. 231-250). New York: Guilford Press.

Shettleworth, S. J., \& Krebs, J. R. (1982). How marsh tits find their hoards: The roles of site preference and spatial memory. Journal of Experimental Psychology: Animal Behavior Processes, 8, 354-375.

Shimamura, A. P. (1986). Priming effects in amnesia: Evidence for a dissociable memory function. Quarterly Journal of Experimental Psychology, 38A, 619-644.

Shimamura, A. P., \& Squire, L. R. (1984). Paired-associate learning and priming effects in amnesia: A neuropsychological study. Journal of Experimental Psychology: General, 113, 556-570.

Sidman, R. L., Green, M. C., \& Appel, S. H. (1965). Catalog of the neurological mutants of the mouse. Cambridge: Harvard University Press.

Slater, P. J. B. (1983). Bird song learning: Theme and variations. In A. H. Brush \& G. A. Clark, Jr. (Eds.), Perspectives in ornithology (pp. 475-499). Cambridge, England: Cambridge University Press.

Smith, H., \& McDougall, W. (1920). Some experiments in learning and retention. British Journal of Psychology, 10, 198-209. 
Squire, L. R. (1982). The neuropsychology of human memory. Annual Review of Neuroscience, 5, 241-273.

Squire, L. R., \& Cohen, N. J. (1984). Human memory and amnesia. In J. McGaugh, G. Lynch, \& N. Weinberger (Eds.), Neurobiology of learning and memory (pp. 3-64). New York: Guilford Press.

Starr, A., \& Phillips, L. (1970). Verbal and motor memory in the amnestic syndrome. Neuropsychologia, 8, 75-88.

Stephens, D. W. (1981). The logic of risk-sensitive foraging preferences. Animal Behaviour, 29, 628-629.

Stephens, D. W., \& Charnov, E. L. (1982). Optimal foraging: Some simple stochastic models. Behavioral Ecology \& Sociobiology, 10, 251263.

Talland, G. A. (1965). Deranged memory. New York: Academic Press.

Taylor, C. P. (1981). Contribution of compound eyes and ocelli to steering of locusts in flight. L. Behavioural analysis. Journal of Experimental Biology, 93, 1-18.

Thomas, G. J. (1984). Memory: Time binding in organisms. In L. R. Squire \& N. Butters (Eds.), Neuropsychology of memory (pp. 374384). New York: Guilford Press.

Thomas, G. J., \& Spafford, P. S. (1984). Deficits for representational memory induced by septal and cortical lesions (singly and combined) in rats. Behavioral Neuroscience, 98, 394-404.

Thorpe, W. H. (1958). The learning of song patterns by birds, with especial reference to the song of the chafinch, Fringilla coelebs. Ibis, 100 , 535-570.

Trivers, R. L. (1971). The evolution of reciprocal altruism. Quarterly Review of Biology, 46, 35-57.

Tulving E. (1972). Episodic and semantic memory. In E. Tulving \& W. Donaldson (Eds.), Organization of memory (pp. 381-403). New York: Academic Press.

Tulving, E. (1983). Elements of episodic memory. Oxford, England: Clarendon Press.

Tulving, E. (1985). How many memory systems are there? American Psychologist, 40, 385-398.

Underwood, G. (1979). Memory systems and conscious processes. In G. Underwood \& R. Stevens (Eds.), Aspects of consciousness (Vol. 1, pp. 91-121). London: Academic Press.
Vander Wall, S. B. (1982). An experimental analysis of cache recovery in Clark's nutcracker. Animal Behaviour, 30, 84-94.

Vieth, W., Curio, E., \& Ernst, U. (1980). The adaptive significance of avian mobbing. III. Cultural transmission of enemy recognition in blackbirds: Cross-species tutoring and properties of learning. Animal Behaviour, 28, 1217-1229.

Warrington, E. K. (1982). The double dissociation of short- and longterm memory deficits. In L. S. Cermak (Ed.), Human memory and amnesia (pp. 61-76). Hillsdale, NJ: Erlbaum.

Warrington, E. K., \& Weiskrantz, L. (1974). The effect of prior learning on subsequent retention in amnesic patients. Neuropsychologia, 12, 419-428.

Warrington, E. K., \& Weiskrantz, L. (1982). Amnesia: A disconnection syndrome? Neuropsychologia, 20, 233-248.

Whitty, C. W. M., \& Zangwill, O. L. (Eds.). (1977). Amnesia (2nd ed.). London: Butterworths.

Wilkinson, G. S. (1984). Reciprocal food sharing in the vampire bat. Nature, $308,181-184$.

Williams, G. C. (1966). Adaptation and natural selection. Princeton, NJ: Princeton University Press.

Wilson, M. (1978). The functional organisation of locust ocelli. Journal of Comparative Physiology A, 124, 297-316.

Wiltschko, W., \& Wiltschko, R. (1976). Interrelation of magnetic compass and star orientation in night-migrating birds. Journal of Comparative Physiology, 109, 91-99.

Zola-Morgan, S., \& Squire, L. R. (1984). Preserved learning in monkeys with medial temporal lesions: Sparing of motor and cognitive skills. Journal of Neuroscience, 4, 1072-1085.

Zola-Morgan, S., \& Squire, L. R. (1985). Complementary approaches to the study of memory: Human amnesia and animal models. In N. W. Weinberger, J. L. McGaugh, \& G. Lynch (Eds.), Memory systems of the brain: Animal and human cognitive processes (pp. 463477). New York: Guilford Press.

Received April 20, 1986

Revision received February 20, 1987

Accepted March 27, 1987

\section{Delworth Appointed Editor of Professional Psychology: Research and Practice, 1989-1994}

The Publications and Communications Board of the American Psychological Association announces the appointment of Ursula M. Delworth, University of Iowa, as editor of Professional Psychology: Research and Practice for a 6-year term beginning in 1989. As of January 1, 1988, manuscripts should be directed to

$$
\begin{gathered}
\text { Ursula Delworth } \\
\text { University of lowa } \\
\text { College of Education } \\
360 \text { LC } \\
\text { Iowa City, Iowa } 52242
\end{gathered}
$$

Manuscript submission patterns for Professional Psychology: Research and Practice make the precise date of completion of the 1988 volume uncertain. The current editor, Norman Abeles, will receive and consider manuscripts until December 31, 1987. Should the 1988 volume be completed before that date, manuscripts will be redirected to Delworth for consideration in the 1989 volume. 